\title{
A Causal Probabilistic Network for Optimal Treatment of Bacterial Infections
}

\author{
Leonard Leibovici, Michal Fishman, Henrik C Schønheyder, Christian Riekehr, \\ Brian Kristensen, Ilana Shraga, and Steen Andreassen
}

\begin{abstract}
The fatality rate associated with severe bacterial infections is about 30 percent and appropriate antibiotic treatment reduces it by half. Unfortunately, about a third of antibiotic treatments prescribed by physicians are inappropriate. We have built a causal probabilistic network (CPN) for treatment of severe bacterial infections. The net is based on modules, each module representing a site of infection. The general configuration of a module is as follows: Major distribution factors define groups of patients, each of them with a definite prevalence of infection caused by a given pathogen. Minor distribution factors multiply the likelihood of one pathogen, without changing much of the prevalence of infection. Infection caused by a pathogen causes local and generalized signs and symptoms. Antibiotic treatment is appropriate if it matches the susceptibility of the pathogens in vitro and appropriate treatment is associated with a gain in life expectancy. This is balanced against the cost of the drug, side effects, and ecological damage, to reach the most cost effective treatment. The net was constructed in such a way that the data for the conditional probability tables will be available, even if it meant sometimes giving up on fine modeling details. For data, we used large databases collected by us in the last 10 years and data from the literature. The CPN was a convenient way to combine data from databases collected at different locations and times with published information. Although the net is based on detailed and large databases, its calibration to new sites requires data that is available in most modern hospitals.
\end{abstract}

Index Terms-Causal probabilistic networks, bacterial infections, bacteremia, antibiotic treatment, cost-effectiveness.

\section{INTRODUCTION}

$\mathrm{T}$ HE fatality rate associated with severe bacterial infections is about 30 percent [1], [2], [3], [4], [5], [6], [7], [8]. Antibiotic drugs are the mainstay of treatment in this condition. Patients treated with appropriate and early antibiotic treatment have a much better chance of survival than patients given inappropriate antibiotics or no antibiotics at all [1], [3], [6], [7], [8].

The suspicion of a severe bacterial infection is usually raised because of nonspecific complaints, the main one being fever. Within the first hour of encountering such a patient, the physician should decide whether the likelihood of a bacterial infection is high enough to start early (and empirical) antibiotic treatment, whether the infection is severe enough to warrant intravenous treatment, and, if so, which antibiotic drug(s) to prescribe.

- L. Leibovici and I. Shraga are with the Department of Internal Medicine, Beilinison Campus, Rabin Medical Center, Petah-Tiqua, Israel 49100. E-mail: \{leibovic, shraga\}@post.tau.ac.il.

- M. Fishman is with the Department of Gastroenterology, Beilinison Campus, Rabin Medical Center, Petah-Tiqva, Israel 49100.

E-mail:arie013@zahav.net.il.

- H.C. Schønheyder and B. Kristensen are with the Department of Clinical Microbiology, Aalborg Hospital, section south, Postbox 365, 9100 Aalborg, Denmark.E-mail: u19212@aas.nja.dk,bkr@miba.auc.dk.

- C. Riekehr is with Hugin Expert A/S, Niels Jernes Vej 10, 9220 Aalborg East, Denmark.E-mail: riekehr@hugin.com.

- S. Andreassen is with the Department of Medical Informatics and Image Analysis, Aalborg University, Fredrik Bajersvej 7 D-2, 9220 Aalborg OE, Denmark.E-mail:msf@miba.auc.dk.

Manuscript received 15 Sept. 1998; revised 12 July 1999; accepted 17 Dec. 1999.

For information on obtaining reprints of this article, please send e-mail to: tkde@computer.org, and reference IEEECS Log Number 112151.
To reach these decisions, the physician is aided by several time-honored associations. The likelihood of a bacterial infection is assessed by the presence of evidence in favor of a localized infection (e.g., an infection of the urinary tract or pneumonia) and by signs and symptoms that are more closely associated with a bacterial infection than with other causes of fever. The severity of infection is estimated mainly by its influence on blood pressure, capillary permeability, and oxygen supply to vital organs (kidneys, lungs, brain). These are mediated through responses of the body and are not specific to the infection [9].

To choose an antibiotic drug, the physician should appraise which are the most likely pathogens of infection, and what their susceptibility to antibiotics is. The main determinant of the pathogen is the site of infection (e.g., urinary tract or the lungs), in addition to other factors, such as the place of acquisition of the pathogen causing the infection (hospital or community), defects in the patient's defense mechanisms, etc. [10]. The patterns of susceptibility to antibiotics differ from region to region and from hospital to hospital. Even in the same hospital, different units have distinct patterns of susceptibility. The main predictor of resistance that is related to the individual patient is whether he has been treated with antibiotics before the present infection [11].

Last, the physician should balance the benefits associated with each antibiotic drug against its detriments. The benefits are coverage (given the likely pathogens and their susceptibility to antibiotics) and activity at the site of infection. These can be translated into a reduction in mortality and morbidity [6]. [8]. The detriments are the cost of the drug, side effects, and development of resistance. 
Unfortunately, the results of these mental computations are often erroneous. About a third of patients with severe bacterial infections are given inappropriate empirical antibiotic treatment and 20 percent are prescribed superfluous drugs [8], [12], [13]. Moreover, the overall balance of antibiotic treatment vs. pathogens is tipping worldwide to the wrong side. Antibiotic drugs account for 20 to 50 percent of a hospital's pharmaceutical expenditure [14]. Resistance to antibiotics is a major problem [15] and strains of bacteria resistant to almost all drugs are emerging [16], [17]. The last major new group of antibiotic drugs was introduced into clinical practice more than a decade ago.

A simple computerized decision support system (DSS) employed at LDS Hospital, Salt Lake City, Utah, was shown to improve antibiotic therapy of individual patients while reducing the costs related to antibiotic treatment and probably curbing the development of resistance [18], [19]. Our experience was similar. We showed that inappropriate antibiotic treatments are biased and that five pathogens accounted for 60 percent of inappropriate treatments, but for only 20 percent of appropriate ones [12]. We built a DSS that was based on the basic distribution of pathogens in our hospital. It used likelihood ratios derived by logistic regression analysis from our databases to adjust the ranking of the five pathogens and to look for patients at high risk of harboring a resistant microorganism. The DSS outperformed the attending physicians at guessing the pathogen of the infection and its susceptibility to antibiotics. It reduced the percentage of inappropriate treatments by half, while prescribing fewer broad-spectrum and costly antibiotics [10].

One problem with the system became evident on analyzing the results. The physician supplied the site of infection to the DSS and, in 20 percent of cases, it was incorrect. A second (and major) problem emerged when trying to transfer the DSS to another location [20]. The adjustment of the logistic models on which the DSS was based to another location required databases similar in size and detail to our original one; although it was quite clear that some factors are universal, some are only local and some needed to be changed.

Nevertheless, it seemed likely that better use of knowledge and data through a computerized DSS can improve the management of patients with severe bacterial infections, while reducing the use of broad-spectrum and costly antibiotics [10], [18], [19]. To obviate the problems of the previous DSSs, we decided to build a normative system, where a causal probabilistic network $(\mathrm{CPN})$ was used to calculate the probability distributions for the relevant output variables and decision theory was used to balance the therapeutic benefit of antibiotic therapy against the detriments associated with antibiotic drugs.

CPNs have been proposed as useful knowledge representation in medicine [21], [22], [23] and have been used for diagnosis [24], [25] and, in combination with decision theory, also for advising on therapy [26]. One of the advantages of using CPNs to represent knowledge is that knowledge derived from literature can be integrated smoothly with data derived from case databases, a property that will be exploited extensively.

\section{Objectives}

The aim of our project was to build a DSS for treatment of patients suspected of harboring a moderate to severe bacterial infection, based on a CPN. An explicit distinction was to be made between local and universal factors, so the calibration of the system to new sites will be natural.

We intended to build a normative system (i.e., corresponding to the real distribution of the population). The input of the DSS should be simple data, readily known or obtainable within hours of suspecting an infection. The outputs the DSS was planned to supply were:

1. the likelihood of a bacterial infection,

2. a measure of its severity,

3 . the most likely site of infection,

4. the most likely pathogen(s),

5. the susceptibility of the pathogens to antibiotic drugs,

6. the gain in life expectancy of the patient related to the treatment with a specific antibiotic drug,

7. the cost of the antibiotic drug, including purchase, side effects, and ecological impact on future resistance, and

8. ranking of the antibiotic drugs according to a summation of 6 and 7, i.e., a cost-effectiveness index.

\section{Resources and Methods}

To obtain the needed data, we used (besides the literature cited below) databases that were collected prospectively by us since 1988. Databases that are available to us include data on approximately 4,000 bacteremic patients seen at Beilinson Campus (Petah-Tiqva, Israel) [6] and about 1,000 bacteremic patients detected in the County of Northern Jutland, Denmark [8]; about 1,400 patients suspected of harboring a moderate to severe bacterial infection [10]; about 400 young women with urinary complaints [27], [28]; and 250 patients with urinary tract infections [29]. The details on each patient included demographic data, underlying disorders, presentation of infection, pathogen and its susceptibility to antibiotics, treatment, and outcome.

The CPN was built with the use of a graphic interface for building of CPNs (HUGIN, Hugin Inc., Aalborg, Denmark). For data handling and analysis, we used the SAS software (SAS Inc., Cary, North Carolina).

\section{Glossary}

Empirical antibiotic treatment: Treatment prescribed before the results of cultures or serological tests (that can point at the pathogen of infection) are known by making an educated guess as to the most likely pathogen and its susceptibility to antibiotics.

Pathogen: A microorganism capable of causing infection in humans.

Resistance and susceptibility to antibiotic drugs: The susceptibility of a microorganism to antibiotic drugs is tested in-vitro, usually by culturing the microorganism on an agar plate on which paper disks impregnated with a fixed amount of an antibiotic drug were placed. The zone of growth-inhibition around the disk is relative to the 


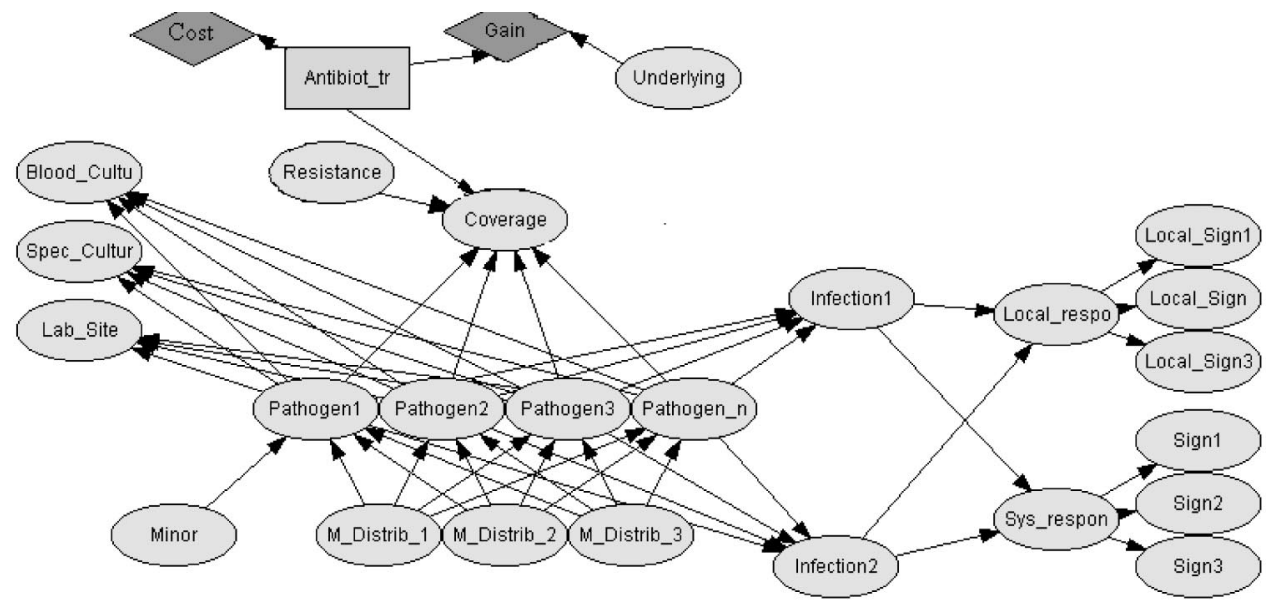

Fig. 1. A general scheme for a site-of-infection network.

susceptibility. A second technique, more expensive and laborious, is to measure the growth of a microorganism in a liquid medium, under exposure to increasing concentrations of an antibiotic drug. There is a good correlation between susceptibility in-vitro and clinical response.

Coverage: The percentage of pathogens of a given infection susceptible to an antibiotic drug.

Plasmid: A ring-like fragment of DNA in bacteria, which can be transferred horizontally to another bacterium by conjugation. Many of the genes resistant to antibiotics reside on plasmids.

\section{A General Model for a Site of Infection}

The CPN was built from distinct modules, each module representing one site of infection. Fig. 1 depicts a general model of a site of infection. Pathogen1 to Pathogen_n represent the potential pathogens of infections at the given site. The states of the Pathogen nodes are severity states, with a risk of mortality associated with each state.

The probability of an infection caused by a Pathogen is determined by its prevalence in major patient-groups (M_Distrib_1 to M_Distrib_3). We selected a factor as defining a major patient-group (a major distribution factor) if it emerged as a strong and independent predictor for infection and distribution of pathogens on statistical analysis of our databases, if, according to present knowledge, it has a clear patho-physiological contribution to the risk of infection at this site, and if the data on the prevalence of infection and distribution of severity-states and pathogens are available.

Several factors qualified as minor distribution factors (Minor), i.e., factors that change the likelihood of one (or a few pathogens) without affecting the overall risk for infection.

Overall, the percentage of polymicrobial infections predicted by the net is less than found in our databases. To overcome this, we need node(s), which link some (or all) of the Pathogen nodes and indicate a breach in the defense mechanisms that is not specific for one pathogen (these nodes are not shown in Fig. 1). Thus, an increase in the likelihood of one pathogen will increase (by a small amount) the likelihood of other pathogens that are linked to it, enough to reach the expected prevalence of polymicrobial infections. For some sites, a mechanism can be postulated for this node (e.g., aspiration for infections of the lungs).

Any of the pathogens can cause an infection and infections can manifest as different patterns (Infection1 and Infection2). Infection will cause a local response (Local_respo), specific to each site of infection, and the local response will manifest as local signs and symptoms, e.g., cough and pains on inspiration caused by pneumonia (Local_sign1 to Local_sign3). It will also cause a systemic response (Sys_respon) common to all sites of infection and manifesting as generalized signs and symptoms (Sign1 to Sign3), such as fever, rapid pulse, and hypotension.

A pathogen causing an infection will grow in local specimens (e.g., urine or sputum, Spec_cultur) and in the blood (Blood_cultu). It can cause other changes, detectable by tests and specific for the site (e.g., leukocytes in the urine, Lab_site).

Antibiotic treatment (Antibiotic_tr) will be appropriate (Coverage) if it matches the in-vitro susceptibility of the pathogens and if it reaches appropriate levels in the blood and at the site of infection. The in-vitro susceptibility is determined by the pathogen and by local factors (mainly time and place of acquisition of infection and prior antibiotic treatment, Resistance).

The net gain in life expectancy obtained by prescribing an antibiotic drug (Gain) is determined by the Coverage and by the underlying disorders of the patient (Underlying). Cost is a utility node associated with antibiotic treatment. For each possible choice of antibiotic therapy, the cost node accounts for the total cost associated with the use of the antibiotic, including the cost of purchasing, side effects, and ecological impact. It is assumed that the best antibiotic therapy is the one with the highest net gain, where the net gain is calculated as the gain minus the cost.

In a complete net that includes all major sites of infection, the sites of infection "compete" with each other to explain the systemic response (Sys_respon), positive blood-cultures (Blood_cultu), and other signs or symptoms that may be common to many sites. Local signs and symptoms (Local_sign1 to Local_sign3), and site-specific laboratory tests (Lab_site) will argue strongly in favor of a specific site. 


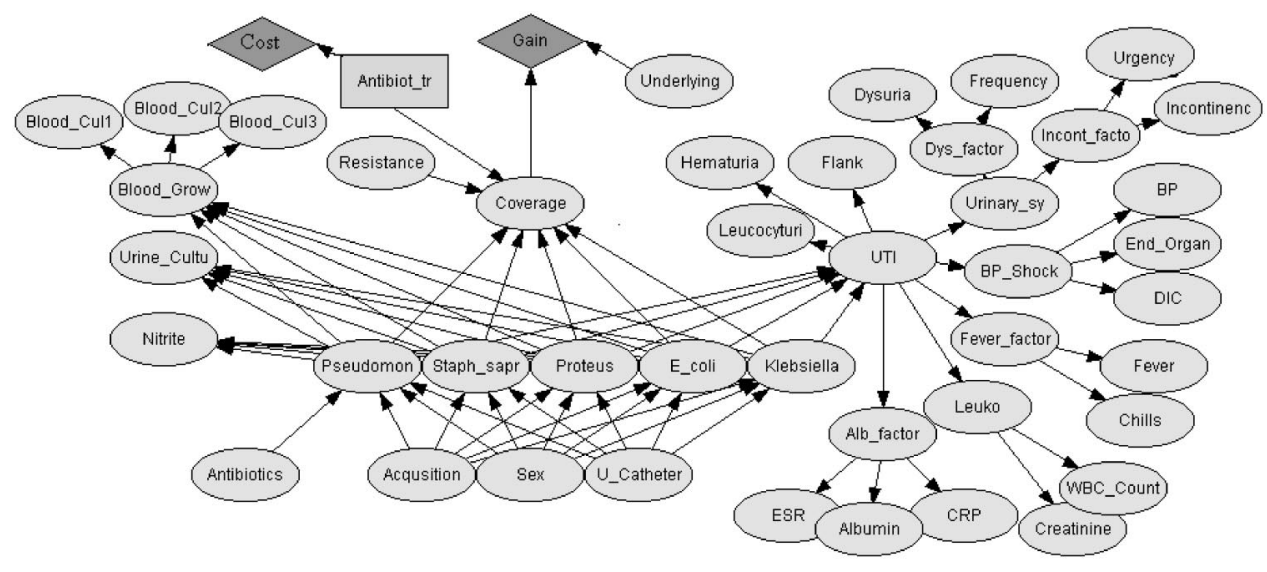

Fig. 2. A network for urinary tract infections.

TABLE 1

States of Major Distribution Factors (see Fig. 2)

\begin{tabular}{|c|c|c|}
\hline Factor & $\begin{array}{c}\text { Node } \\
\text { Identifier }\end{array}$ & States \\
\hline $\begin{array}{l}\text { Place and time of } \\
\text { acquisition of UTI }\end{array}$ & Acquisition & $\begin{array}{l}\text { 1) Community } \\
\text { 2) Nursing home } \\
\text { 3) Hospital, duration of stay } \leq 2 \text { days } \\
\text { 4) Hospital, medical department, duration } \\
\text { of stay }>2 \& \leq 7 \text { days } \\
\text { 5) Hospital, surgical department, duration } \\
\text { of stay }>2 \& \leq 7 \text { days } \\
\text { 6) Hospital, medical department, duration } \\
\text { of stay }>7 \text { days } \\
\text { 7) Hospital, surgical department, duration } \\
\text { of stay }>7 \text { days } \\
\text { 8) Intensive care unit }\end{array}$ \\
\hline Gender & Sex & $\begin{array}{l}\text { 1) Female } \\
\text { 2) Male }\end{array}$ \\
\hline Indwelling urinary catheter & U_Catheter & $\begin{array}{l}\text { 1) Present for }>24 \text { hours in the last } 2 \\
\text { weeks } \\
\text { 2) Absent }\end{array}$ \\
\hline
\end{tabular}

In their absence, the a priori prevalence of infections in the population takes precedence. The overall Gain constitutes from the gain at each site. Most of the time, one site will predominate.

\section{EXAMPLE OF A SPECIFIC Site: INFECTIONS OF THE URINARY TRACT}

Fig. 2 depicts a net for urinary tract infections (UTI). For simplicity's sake, only five of 12 pathogens are presented, and some of the other nodes (e.g., some minor distribution factors and the details on blood cultures) were omitted. In this version, the net was calibrated for Beilinson Hospital, Petah-Tiqva, Israel.

\subsection{Prevalence of Infection and Distribution of Pathogens}

As an approximation for prevalence of new infections, we used daily incidence. The major determinants for the incidence of UTI and the distribution of the pathogens are the place and time of acquisition of infection (Acquisition), gender (Sex), and the presence of an indwelling urinary catheter (U_Catheter) [29]. The states of these nodes are given in Table 1. The states of the pathogen nodes (Escherichia coli (E_coli), Klebsiella pneumoniae (Klebsiella), etc.) are detailed in Table 2.

Thus, we are looking at an $8 \times 2 \times 2$ table for each pathogen. The source of data for each layer is given in Table 3. Obtaining the data involves two separate questions: What is the incidence of UTI in a given patient-group (e.g., what is the percentage of women without a catheter in the community that have asymptomatic UTI, cystitis, etc.) and what is the percentage of UTI caused by the specific pathogen? The first question probably addresses universal factors: We can assume that the predisposition to infection and its severity are related to biological risk-factors, which are not much different all over the world. Table 3 details the sources of data for the incidence of urinary tract infections according to the major distribution factors. The only item for which data was completely missing in our databases 
TABLE 2

States of the Pathogens Nodes (Escherichia coli (E_coli), Klebsiella pneumoniae (Klebsiella), etc.)

\begin{tabular}{|l|l|c|c|}
\hline \multicolumn{1}{|c|}{ State } & \multicolumn{1}{|c|}{ Description } & $\begin{array}{c}\text { Fatality } \\
(\%)\end{array}$ & $\begin{array}{c}\text { Bacteremia } \\
(\%)\end{array}$ \\
\hline No & No infection caused by the pathogen & 0 & 0 \\
\hline Asymptomatic & $\begin{array}{l}\text { Laboratory evidence of infection without } \\
\text { signs or complaints }\end{array}$ & 0 & 0 \\
\hline Cystitis & $\begin{array}{l}\text { Urinary complaints, without fever or other } \\
\text { signs and symptoms of a systemic } \\
\text { response }\end{array}$ & 0 & 0.01 \\
\hline Pyelonephritis & $\begin{array}{l}\text { Urinary infection with a systemic } \\
\text { response and/or evidence for involvement } \\
\text { of the kidneys }\end{array}$ & 1 & 10 \\
\hline Urosepsis & $\begin{array}{l}\text { Urinary infection with manifestations of } \\
\text { sepsis }\end{array}$ & 10 & 30 \\
\hline Septic shock & Septic shock & 60 & 60 \\
\hline
\end{tabular}

The states were defined in such a way as to correspond to conventional clinical entities, but also to outline groups with a fixed and increasing likelihood of fatality (associated with the infection) and bacteremia.

was the incidence of asymptomatic bacteriuria and that was drawn from the literature [30], [32], [34], [36], [37], [39], [41], [42], [45]. For the rest of the data, we calculated incidence data from our databases (number of infections per year per population in our cachement area), but checked that the data was within the interval reported in the literature (Table 4).

The frequency of pathogens and susceptibility to antibiotics are specific to the location. Thus, the answer to the second question can be obtained entirely from our databases, but for the distribution of bacteria that cause asymptomatic bacteriuria. An example, part of the final conditional probability table for the node $\mathbf{E}_{-}$coli, is given in Table 5.

The minor distribution factor shown in Fig. 2 is an antibiotic treatment prior to the infection (Antibiotics). Prior antibiotic treatment multiplies the likelihood of an infection caused by Pseudomonas aeruginosa (Pseudomon) by a factor of 2 . This ratio is a result of multivariable logistic analyses and independent of other factors [29], [52]. We assumed that the net effect of prior antibiotic treatment on the prevalence of UTI is negligible.

The a priori distribution for the parent nodes was obtained from official publications (male: female ratios, age distribution, and number of hospital and nursing beds in the Beilinson cachement area [53], [54]); literature (percentage of people with an indwelling urinary catheter in and out of hospital [55], [56] and percentage of prior antibiotic treatment in the general population and in inpatients [57], [58]).

\subsection{Signs and Symptoms of Urinary Tract Infection: Local Manifestations}

The manifestations of UTI do not depend on the pathogen. The local complaints associated with UTI are dysuria (burning on urination, Dysuria), frequent micturition (Frequency), urgency (Urgency), suprapubic pain (Supra), and incontinence (Incontinenc). The main problem with using the presence of these complaints to favor a bacterial
UTI is that the complaints are highly correlated. If we were to count them separately, we will grossly exaggerate the strength of the evidence in favor of UTI.

To address these problems, we performed a factor analysis on the matrix of urinary complaints in patients with urinary complaints and UTI. Factor analysis builds new axes (factors), perpendicular to each other, where each factor represents correlations between variables. Thus, the dimensions of the matrix are reduced while keeping as much as possible of the original variance. Two factors explained more than 80 percent of the variance in the urinary complaints matrix. The first represented the correlation of dysuria, frequency, and suprapubic pain. The variables that contributed to the second factor were frequency and incontinence (Table 6). We dichotomized the factors by using the mean of the factor as the division point.

Thus, the following net was reached: UTI causes urinary symptoms (Urinary_sy), which causes Dys_factor, a nonobservable factor. Dys_factor causes Dysuria, Frequency, Urgency, and Supra (suprapubic pain). Urinary_sy also causes a second nonobservable factor, Incont_factor, which leads to complaints of frequency and incontinence. (Fig. 2).

Flank pain (Flank) is a sign of kidney infection and the data was derived directly from our databases. The percentage of leukocyturia (Leukocyturi) and hematuria (Hematuria) in patients with UTI (the presence of white and red blood cells in the urine) was similar in our databases and in the literature [48], [59], [60]. To complete the tables, the percentage of each urinary symptom, leukocyturia, and hematuria in the general population (without urinary infections) was abstracted from the literature [56], [59], [61], [62], [63], [64], [65], [66], [67], [68].

\subsection{Signs and Symptoms of Urinary Tract Infection: Systemic Response}

The systemic response to infection affects many clinical variables (temperature, pulse, blood pressure, white blood cell count, serum creatinine, urea, and albumin, etc.). These 
TABLE 3

Sources of Data for the Incidence of UTI and Distribution of Pathogens, According to Place and Time of Acquisition

\begin{tabular}{|c|c|c|}
\hline \multirow{2}{*}{\begin{tabular}{|c|} 
Place and time of \\
acquisition of UTI (states \\
of the Acquisition node) \\
\end{tabular}} & \multicolumn{2}{|c|}{ Source of data } \\
\hline & Prevalence of UTI & Distribution of pathogens \\
\hline Community & Lit. (ref $(30-35))$ & LDB (ref (27-29)) \\
\hline Nursing home & Lit. $(\operatorname{ref}(30,33,36-40))$ & $\begin{array}{r}\text { Lit. }(\operatorname{ref}(36,41-48)) \& \text { LDB } \\
(\operatorname{ref}(6,29))\end{array}$ \\
\hline $\begin{array}{l}\text { Hospital, duration of stay } \\
\leq 2 \text { days }\end{array}$ & LDB (ref $(6,29))$ & LDB (ref $(6,29))$ \\
\hline $\begin{array}{l}\text { Hospital, medical } \\
\text { department, duration of } \\
\text { stay }>2 \& \leq 7 \text { days }\end{array}$ & LDB (ref $(6,10,29))$ & $\operatorname{LDB}(\operatorname{ref}(6,10,29))$ \\
\hline $\begin{array}{l}\text { Hospital, surgical } \\
\text { department, duration of } \\
\text { stay }>2 \& \leq 7 \text { days }\end{array}$ & LDB $(\operatorname{ref}(6))$ & LDB (ref (6)) \\
\hline $\begin{array}{l}\text { Hospital, medical } \\
\text { department, duration of } \\
\text { stay }>7 \text { days }\end{array}$ & LDB $(\operatorname{ref}(6,10,29))$ & $\operatorname{LDB}(\operatorname{ref}(6,10,29))$ \\
\hline $\begin{array}{l}\text { Hospital, surgical } \\
\text { department, duration of } \\
\text { stay }>7 \text { days }\end{array}$ & LDB (ref (6)) & LDB (ref (6)) \\
\hline Intensive care unit & $\begin{array}{r}\text { Lit. (ref }(31,33,49-51)) \& \\
\text { LDB (ref (6)) }\end{array}$ & $\begin{array}{r}\text { Lit. }(\operatorname{ref}(50,51)) \& \text { LDB } \\
(\operatorname{ref}(6))\end{array}$ \\
\hline
\end{tabular}

Lit.-Literature

LDB - Local databases

TABLE 4

Daily Incidence of Urinary Tract Infection in Women without a Urinary Catheter, Grouped by the Place and Time of Acquisition, per 100

\begin{tabular}{lllllrlrl}
\hline & Com & Nurs & H,<2d & $\mathbf{M , 2 - 7 d}$ & $\mathbf{M},>\mathbf{7 d}$ & $\mathbf{S , 2 - 7 d}$ & $\mathbf{S , > 7 d}$ & $\mathbf{I C U}$ \\
Asymptomatic & 1.33 & 8.83 & 3.13 & 9.00 & 10.80 & 9.00 & 11.00 & 1.26 \\
Cystitis & 0.10 & 0.66 & 0.77 & 1.00 & 1.28 & 1.20 & 2.20 & 0.32 \\
Pyelonephritis & 0.005 & 0.06 & 1.65 & 0.48 & 1.86 & 0.42 & 1.61 & 0.45 \\
Urosepsis & 0.002 & 0.05 & 0.64 & 0.18 & 0.70 & 0.16 & 0.63 & 0.17 \\
Septic shock & 0.000 & 0.002 & 0.07 & 0.02 & 0.07 & 0.02 & 0.06 & 0.02 \\
\hline
\end{tabular}

Com: Community acquired; Nurs: Nursing home; $\boldsymbol{H , < 2 d : ~ C o m m u n i t y ~ a c q u i r e d , ~ b u t ~ a d m i t t e d ~ t o ~ h o s p i t a l ; ~} \boldsymbol{M}$, 2-7d: Acquired in a department of medicine during the first week of hospital stay. M,>7d: Acquired in a department of medicine after the first week of hospital stay; S: surgical department as opposed to medical; ICU: acquired in the intensive care unit.

variables are again highly correlated. Factor analysis showed four factors to account for more than 80 percent of the variance of the original matrix:

1. BP_Shock: The variables contributing to these factors were blood pressure (BP), evidence of disseminated intravascular coagulopathy (DIC), and evidence of other end-organs involvement (End_Organ).

2. Fever_factor: Main contributions from body temperature on admission (Fever) and the presence of chills (Chills).

3. Leuko: A factor that shows a correlation between the white blood cell count (WBC_Count) and serum creatinine (Creatinine).

4. Alb_factor: Main contributions from serum albumin (Albumin), erythrocyte sedimentation rate (ESR), and C-reactive protein (CRP).
Data were obtained from the local databases and information on the distribution of the body temperature, serum creatinine and albumin, erythrocyte sedimentation rate, etc., in the normal population-from the literature [69], [70], [71], [72], [73]. To give an example of the conditional probabilities, Table 7 shows the dependency of Fever_factor on UTI and Table 8 the conditional probability of Fever, given Fever_factor.

The four factors are statistical constructs. The inflammatory systemic effects are caused by mediators (mostly cytokines) released by macrophages in response to bacterial products [9]. Carlstedt et al. [74] tested the levels of the two main proinflammatory cytokines, tumor necrosis factor $\alpha$; (TNF- $\alpha$;) and interleukin 6 (IL-6), in a group of 140 patients. We performed a factor analysis on their data with similar results to our own. It was of interest to note that IL-66 had a major contribution to the Fever_factor (loading of 0.91) and to no other factor, while $\mathrm{TNF}-\alpha$; contributed to the 
TABLE 5

Daily Incidence of Urinary Tract Infections Caused by Escherichia coli, per 1,000: Conditional Probability Table for Node E_coli

\begin{tabular}{|l|r|r|r|r|r|r|r|r|}
\hline \multicolumn{1}{|c|}{ Sex } & \multicolumn{10}{|c|}{ female } \\
\hline U_Catheter & \multicolumn{1}{|c|}{ no } \\
\hline \multicolumn{1}{|c|}{ Acquisition } & \multicolumn{1}{c|}{ Com } & \multicolumn{1}{c|}{ Nurs } & \multicolumn{1}{c|}{ H,<2d } & M,2-7d & M,>7d & \multicolumn{1}{c|}{ S,2-7d } & \multicolumn{1}{c|}{,>7d } & \multicolumn{1}{c|}{ ICU } \\
\hline No UTI & 977.3 & 945.4 & 949.7 & 911.9 & 928.0 & 914.1 & 929.7 & 998.2 \\
\hline Asymptomatic & 20.9 & 49.8 & 26.8 & 78.2 & 55.6 & 80.4 & 52.6 & 1.00 \\
\hline Cystitis & 1.69 & 4.21 & 5.90 & 6.00 & 5.56 & 3.71 & 8.85 & 0.27 \\
\hline Pyelonephritis & 0.04 & 0.38 & 12.33 & 2.77 & 7.78 & 1.24 & 6.22 & 0.33 \\
\hline Urosepsis & 0.017 & 0.16 & 4.72 & 1.07 & 2.78 & 0.43 & 2.39 & 0.13 \\
\hline Septic shock & 0.000 & 0.017 & 0.54 & 0.12 & 0.28 & 0.05 & 0.24 & 0.02 \\
\hline
\end{tabular}

Only part of the table is shown: Female patients, with no urinary catheter, for all the states of Acquisition (place and time of acquisition of infection). For states of the Acquisition node, see Table 1.

TABLE 6

Factor Analysis of the Matrix of Urinary Complaints, Coded from 0 (absent) to 3 (maximum) in 398 Patients with Urinary Tract Infection

\begin{tabular}{lrc}
\hline \multicolumn{1}{c}{ Complaint } & Factor1 & Factor2 \\
Dysuria & $\mathbf{0 . 8 2}$ & 0.09 \\
Frequency & $\mathbf{0 . 5 7}$ & 0.32 \\
Supra-pubic pain & $\mathbf{0 . 8 0}$ & 0.02 \\
Urgency & 0.11 & $\mathbf{0 . 8 3}$ \\
Incontinence & 0.07 & $\mathbf{0 . 5 8}$ \\
\hline
\end{tabular}

The table shows the loading of the variables on the two main factors. Loading of $>0.5$ was considered as significant and is emphasized in bold type.

TABLE 7

Urinary Tract Infection (UTI) Causes the Elevation of an Unobservable Factor (Fever_factor, probably IL-6): Conditional Probability Table for Fever_factor

\begin{tabular}{|c|c|c|c|c|c|c|}
\hline $\begin{array}{l}\text { States of } \\
\text { Fever_fa } \\
\text { ctor }\end{array}$ & \multicolumn{7}{|c|}{ States of UTI } \\
\hline & No UTI & $\begin{array}{c}\text { Asympto } \\
\text { matic }\end{array}$ & Cystitis & $\begin{array}{c}\text { Pyelonep } \\
\text { hritis }\end{array}$ & Urosepsis & $\begin{array}{c}\text { Septic } \\
\text { shock }\end{array}$ \\
\hline Very low & 999 & 999 & 990 & 9.9 & 9.9 & 9.9 \\
\hline Low & 0.7 & 0.7 & 7 & 297 & 277.0 & 208.0 \\
\hline High & 0.3 & 0.3 & 3 & 693.1 & 713.1 & 782.1 \\
\hline
\end{tabular}

The total of each column is 1,000 patients.

BP_Shock factor (loading of 0.50). Thus, Fever_factor can be renamed as IL- 6 and given real units and TNF- $\alpha$ is probably a major cause of BP_Shock. This preliminary analysis shows that the four factors are not peculiar to our databases and that the statistical constructs have biological correspondences which can be measured.

\subsection{Urinary Tract Infection: Bacteriological Tests}

Growth of microorganisms in the urine can be currently detected by two means. Some pathogens reduce nitrate to nitrite and that can be detected by a simple dipstick test. The sensitivity and specificity of the nitrite test (Nitrite) for each pathogen was derived from the literature [75], [76], [77]. The urine can be cultured on an agar plate (Urine_Cultu). The false positive rate of a growth on agar is about 20 percent because of external contamination of the urine. This is the number of patients in our database with a positive urine culture, but no other evidence of UTI, out of the total number of patients with positive cultures. The false negative rate is again about 20 percent. To reach this number, we looked at patients with urinary complaints, leukocytes in the urine, a positive blood culture, and a negative urine culture, out of the total number of patients with bacteremic UTI.

Growth of microorganisms in the blood (Blood_Grow) is detected by injecting $20 \mathrm{ml}$ of asseptically drawn blood into two bottles (a set) containing different growth media. The procedure is repeated two to three times (Blood_cul1 to Blood_cul3). The bottles are incubated and growth is detected automatically by an increase in infrared adsorption caused by a rise of $\mathrm{CO}_{2}$ in the bottle. The fluid in the bottle is stained to look for microorganisms and it is cultured again on agar plates to identify the microorganisms and to test for susceptibility to antibiotics. Local data was used to assess the false positive and false negative rates of each step and to predict the pathogen by its features in the stained preparation. 
TABLE 8

The Distribution of Body Temperature (Fever) According to the States of Fever_factor.

\begin{tabular}{|c|c|c|c|}
\hline $\begin{array}{c}\text { States of Fever (body } \\
\left.\text { temperature, }{ }^{0} \mathrm{C}\right)\end{array}$ & \multicolumn{3}{|c|}{ States of Fever_factor } \\
\hline & Very low & \multicolumn{1}{|c|}{ Low } & High \\
\hline$<36.0$ & 59.7 & 0.01 & 37.0 \\
\hline $36.1-36.5$ & 149.7 & 10.0 & 37.0 \\
\hline $36.6-38.0$ & 788.3 & 277.2 & 556.0 \\
\hline $38.1-38.6$ & 2.0 & 198.0 & 185.0 \\
\hline$>38.7$ & 0.001 & 514.8 & 185.0 \\
\hline
\end{tabular}

Conditional probability table for Fever. The total of each column is 1,000 patients.

\subsection{Antibiotic Treatment: Resistance, Coverage, and Gain}

The susceptibility of a pathogen to antibiotic drugs is determined by intrinsic factors of the pathogen and by acquired features. The strongest predictors of resistance are acquisition of infection in the hospital and antibiotic treatment in the month preceding the present infection [11].

Usually, a single antibiotic drug is prescribed, but treatment of severe infections with two drugs is not unusual. There are three reasons commonly given for that: 1) to increase the spectrum covered by empirical antibiotic treatment; 2) to use drugs that are synergistic; and 3) to try and prevent the development of resistance to one drug. Resistance to different antibiotic drugs is not independent, mainly because the genetic information on resistance to several drugs can be transmitted on the same plasmid. Thus, the coverage afforded by two drugs is not a simple multiplication of their coverage, but usually less than that, and should be derived from local data.

Therefore, the coverage of a pathogen (Coverage) depends on whether the pathogen caused an infection or not (the pathogen node, e.g., E_coli), which antibiotic(s) were prescribed (Antibiotic_tr), whether the infection was acquired in the hospital, and whether the patient was given prior antibiotic treatment (Resistance). We included in the net 26 antibiotic drugs that are used for treatment of moderate to severe infections and one additional state for no treatment. Thus, we are looking at a table of $27 \times 27 \times 3$. However, some of the cells are a priori empty, as certain drugs are used only against a few microorganisms and not against others. Local data on the susceptibility of pathogens in the different subgroups were available from microorganisms that grew in blood-cultures.

Given the underlying condition of the patient (Underlying), including data on age, functional capacity, neutropenia, malignancy, atherosclerotic heart disease, congestive heart failure, serum albumin and creatinine, and sex, we can calculate the patient's life expectancy [6]. Coverage by an antibiotic drug will increase the chance of a 30-day survival by an odds-ratio of 1.6 [78]. Thus, we can calculate in life years what the Gain associated with each drug is. To do this, a synergistic combination of drugs will add (only for some pathogens and conditions) a small benefit. Appropriate antibiotic treatment is associated with a short- er stay in the hospital (by a median of one day) and, thus, with less expense.

Each drug has an associated cost, with contributions from cost of purchase, side effects, and development of future resistance. To calculate the net gain, i.e., the difference between Gain and Cost, we have used the common assumption in medicine that one life year is the equivalent of $\$ 55,000$, this being the cost of keeping a patient with chronic renal failure on hemodialysis for one year.

\section{Comments}

We have built a CPN to support decisions for treatment of bacterial infections. The CPN includes such elements that were thought by us to be crucial for the initial management of an infection. Our considerations included, from the beginning, availability of the data for the conditional probabilities tables, even if it meant sometimes giving up on fine modeling details. For example, a detailed causal model is available for the correlation between resistance to antibiotic drugs. Some of the correlation is explained by common mechanisms (e.g., an enzyme that can inactivate a whole family of antibiotics). Some is accounted for by linkage of genetic data on transposons and plasmids. However, data on the prevalence of these vectors in hospitals is lacking and we chose the less elegant solution of using a $27 \times 27 \times 3$ matrix for which data were available. The advantage of a causal net is that these avenues can be explored to generate and test hypotheses while using the present version for decision support.

The part of the net on systemic response to infection is a good example of that. We started with a statistical construct (factors derived by factor analysis) to reduce the dimensions of the matrix and to avoid repetitive donations of correlated variables. It turned out that the statistical factors have biological correspondences. We continue to develop this part of the net, not only as a support decision tool, but also to generate and test hypotheses on the clinical meaning of mediators in infection.

In many medical situations, we observe a number of manifestations, which are obviously correlated (e.g., all urinary complaints or septic manifestations). Counting them separately as evidence will induce bias. To reduce the dimensions of the matrix while retaining as much of the variance of the original dataset as possible (usually $>80$ percent), we used factor analysis. This technique builds a number of factors (fewer than the original number of variables), which represent correlations among the original variables. The factors are rotated so the contribution of the variables to factors will be as close as possible to 0 or \pm 1 . The final factors are uncorrelated with each other [79].

For our purposes, factor analysis offers a number of advantages. The donation of correlated variables is counted just once. Many times, the common factors correspond to a real biological vector. It also reduces the problem of missing data while using the system. (If a factor causes a number of manifestations, even if one of the manifestations is unobservable in a patient, the others will probably provide a good approximation as to the magnitude of the common 
TABLE 9

Data Needed to Calibrate the System To a New Location

\begin{tabular}{|c|c|c|}
\hline Data & Source & Availability \\
\hline $\begin{array}{l}\text { Incidence of infections in } \\
\text { the population, according } \\
\text { to the strata of the major } \\
\text { distribution factors }\end{array}$ & $\begin{array}{l}\text { 1) Computerised hospital } \\
\text { records } \\
\text { 2) Administrative data } \\
\text { 3) Demographic data on } \\
\text { the hospital cachement } \\
\text { area. }\end{array}$ & $*$ \\
\hline $\begin{array}{l}\text { Distribution of pathogens, } \\
\text { according to site of } \\
\text { infection and major } \\
\text { distribution factors }\end{array}$ & $\begin{array}{l}\text { 1) Laboratory and clinical } \\
\text { hospital records } \\
\text { 2) Regional and national } \\
\text { data }\end{array}$ & $* *$ \\
\hline $\begin{array}{l}\text { Susceptibility of } \\
\text { pathogens, according to } \\
\text { place of acquisition and } \\
\text { prior use of antibiotics }\end{array}$ & Hospital records & $* * *$ \\
\hline $\begin{array}{l}\text { Costs of antibiotic and } \\
\text { administration, costs } \\
\text { related to hospital-stay }\end{array}$ & Administrative data & $* * *$ \\
\hline
\end{tabular}

* Available in some hospitals; can be guessed or assessed.

** Available in most hospitals; can be guessed or assessed.

${ }^{* * *}$ Available in almost all hospitals.

TABLE 10

Decision-points in Managing Patients with a Bacterial Infection

\begin{tabular}{|c|c|c|}
\hline Time & Description of decision-point & DSS output \\
\hline $30-45 \min$ & $\begin{array}{l}\text { History, physical examination and } \\
\text { preliminary tests available }\end{array}$ & $\begin{array}{l}\text { 1) Most likely site of infection } \\
\text { 2) Most likely pathogen/s and } \\
\text { susceptibility to antibiotics } \\
\text { 3) Estimate as to severity of } \\
\text { infection } \\
\text { 4) Preferable antibiotic drug/s } \\
\text { 5) Details on drug/s (e.g. side- } \\
\text { effects) }\end{array}$ \\
\hline $1-2 \mathrm{~h}$ & Direct stains available & idem, revised \\
\hline $24-48 \mathrm{~h}$ & $\begin{array}{l}\text { Cultures negative; an estimate on } \\
\text { how the infection responded to } \\
\text { empirical treatment is available. }\end{array}$ & idem, revised \\
\hline $24-48 \mathrm{~h}$ & $\begin{array}{l}\text { Cultures positive and results } \\
\text { available }\end{array}$ & $\begin{array}{l}\text { 1) Most likely site of infection } \\
\text { 2) Estimate as to severity of } \\
\text { infection } \\
\text { 3) Preferable antibiotic drug/s } \\
\text { 4) Details on drug/s (e.g. side- } \\
\text { effects) }\end{array}$ \\
\hline
\end{tabular}

Time 0 is on encountering the patient for the first time.

factor). To our knowledge, factor analysis has not been used previously to shape a CPN from a database. We intend to explore if other "data mining" methods [80], [81] will uncover the same structure of the CPN as the one derived by the use of factor analysis.

Strictly speaking, the whole net is not a CPN, but is quite similar to an influence diagram [82]. Acknowledging the influence diagram tradition, we have used diamond shapes to represent utility nodes (Gain and Cost) and squares to represent decision nodes (Antibiotic_Tr). We have chosen not to call the net an influence diagram because we have used a different algorithm [22] to solve the influence diagram.

For accreting evidence, we used databases that were collected in two different countries at several locations and at different points in time and data from the literature. Many times publications supply different numbers for the same relation. To obtain one estimate from the published data, we weighted the parameters by inverse-variance, using a fixed-effect model [83].

The databases that were used for extraction of data were analyzed before, using statistical methods. The "knowl- 
edge" incorporated in the CPN is both knowledge in the classical sense and insights derived from analysis of the databases. The causal network turned out to be an ideal tool for combining knowledge with data and data from several sources. There is no other methodology used for decision support in medicine that allows the combination of data from several sources with knowledge with such ease.

How convenient will it be to transfer and calibrate the system to another location? Although the data that was used to build it is extensive, we can state explicitly which data is needed to calibrate it to a new location (Table 9). The data is available (or can be easily estimated) in most hospitals, often on magnetic media.

The main purpose in constructing the CPN was to use it in a DSS to improve treatment of infections. The first step before developing a DSS is to ask whether the problem we address is real, whether the decision-makers are in need of help, and what our criteria for improvement of process and outcome are. We have shown that the fatality associated with severe infections is substantial [6], that it is reduced by appropriate antibiotic treatment regardless of other riskfactors for fatality [6], [8], [78], and that the physicians often err in prescribing treatment. This situation involves an objective process variable (the rate of appropriate antibiotic treatments) and fatality can be used as the outcome variable.

The CPN addresses all the important decision-points in the first days of managing a patient suspected or known to have a bacterial infection (Table 10). Based on previous experience [10], [18], [19], we expect the CPN to perform better than the clinician, but will it improve clinical practice and patient's outcome? The answer probably depends on more factors than just the performance of the system. The user's interaction with the system should be as convenient as possible. In a computerized environment, most of the data can be imported into the system, saving the physician the need to enter it manually. The encounter between the user and the system can be initiated by the system, as well as by the user. In a computerized environment, the system can initiate an encounter if an antibiotic drug was prescribed, if growth was detected in a blood culture, or even if a patient with fever or other possible evidence of infection was entered into the hospital computerized database.

The ultimate question that must be answered is whether the system can be shown, in a clinical trial, to improve process and outcome variables, i.e., increase the percentage of appropriate antibiotic treatments, curtail costs and use of broad-spectrum antibiotics, reduce the fatality rate associated with infection, and curb progress of future resistance.

\section{REFERENCES}

[1] C.S. Bryan, K.L. Reynolds, and E.R. Brenner, "Analysis of 1,186 Episodes of Gram-Negative Bacteremia in Non-University Hospitals: The Effects of Antimicrobial Therapy," Rev. of Infectious Diseases, vol. 5, pp. 629-638, 1983.

[2] M.P. Weinstein, J.R. Murphy, L.B. Reller, and K.A. Lichtenstein, "The Clinical Significance of Positive Blood Cultures: A Comprehensive Analysis of 500 Episodes of Bacteremia and Fungaemia in Adults II. Clinical Observations, with Special Reference to Factors Influencing Prognosis," Rev. of Infectious Diseases, vol. 5, pp. 54-70, 1983.
[3] P. Ispahani, N.J. Pearson, and D. Greenwood, "An Analysis of Community and Hospital-Acquired Bacteraemia in a Large Teaching Hospital in the United Kingdom," Quarterly J. Medicine, vol. 63, pp. 427-440, 1987.

[4] J.B. Haug, S. Harthug, T. Kalager, A. Digranes, and C.O. Solberg, "Bloodstream Infections at a Norwegian University Hospital, 1974-1979 and 1988-1989: Changing Etiology, Clinical Features and Outcome," Clinical Infectious Diseases, vol. 19, pp. 246-56, 1994.

[5] D. Pittet and R.P. Wenzel, "Nosocomial Bloodstream Infections: Secular Trends in Rates, Mortality, and Contribution to Total Hospital Deaths," Archives of Internal Medicine, vol. 155, pp. 1,1771,184, 1995.

[6] L. Leibovici, Z. Samra, H. Konigsberger, M. Drucker, S. Ashkenazi, and S.D. Pitlik, "Long-Term Survival Following Bacteremia or Fungemia," J. Am. Medical Assoc., vol. 274, pp. 807-812, 1995.

[7] G.R. Jones and J.A. Lowes, "The Systemic Inflammatory Response Syndrome as Predictor of Bacteraemia and Outcome from Sepsis," Quarterly J. Medicine, vol. 89, pp. 515-522, 1996.

[8] G. Pedersen, H.C. Schønheyder, and H.T. Sørensen, "Antibiotic Therapy and Outcome of Monomicrobial Gram-Negative Bacteraemia: A 3-year Population Based Study," Scandinavian J. Infectious Diseases, vol. 29 pp. 601-606, 1997.

[9] R.C. Bone, "Toward a Theory Regarding the Pathogenesis of the Systemic Inflammatory Response Syndrome: What We Do and Do Not Know about Cytokine Regulation," Critical Care Medicine, vol. 24 pp. 163-172, 1996.

[10] L. Leibovici, V. Gitelman, Y. Yehezkelli, O. Poznanski, G. Milo, M. Paul, and P. Ein-Dor, "Improving Empirical Antibiotic Treatment: Prospective, Nonintervention Testing of a Decision Support System," J. Internal Medicine, vol. 242, pp. 395-400, 1997.

[11] L. Leibovici, H. Konigsbereger, S.D. Pitlik, Z. Samra, and M. Drucker, "A Predictive Index Optimizing Empiric Treatment of Gram-Negative Bacteremia," J. Infectious Diseases, vol. 163, pp. 193$196,1991$.

[12] L. Leibovici, H. Konigsberger, S.D. Pitlik, Z. Samra, and M. Drucker, "Patients at Risk for Inappropriate Antibiotic Treatment of Bacteremia," J. Internal Medicine, vol. 231, pp. 371-374, 1992.

[13] D.G. Maki and A.A. Schune, "A Study of Antibiotic Misuse in a University Hospital," Am. J. Medical Sciences, vol. 275, pp. 271-82, 1978.

[14] J.R. Berman, F.K. Zaran, and M.J. Rybak, "Pharmacy-Based Antimicrobial Monitoring Service," Am. J. Hospital Pharmacy, vol. 49, pp. 1,701-1706, 1992.

[15] A. Tomasz, "Multiple Antibiotic Resistant Pathogenic Bacteria," New England J. Medicine, vol. 330, pp. 1,247-1,251, 1994.

[16] J.G. Morris, D.K. Shay, J.N. Hebden, R.J. McCarter, B.E. Perdue, W. Jarvis, J.A. Johnson, T.C. Dowling, L.B. Polish, and R.S. Schwalbe, "Enterococci Resistant to Multiple Antimicrobial Agents, Including Vancomycin: Establishment of Endemicity in a University Medical Center," Annals of Internal Medicine, vol. 123, pp. 250-259, 1995.

[17] E.S. Go, C. Urban, J. Burns, B. Kreiswirth, W. Eisner, N. Mariano, K. Mosinka-Snipas, and J.J. Rahal, "Clinical and Molecular Epidemiology of Acinetobacter Infections Sensitive Only to Polymyxin B and Sulbactam," Lancet, vol. 344 pp. 1,329-1,332, 1994.

[18] S.L. Pestotnik, D.C. Classen, R.S. Evans, and J.P. Burke, "Implementing Antibiotic Practice Guidelines through ComputerAssisted Decision Support: Clinical and Financial Outcomes," Annals of Internal Medicine, vol. 124, pp. 884-890, 1996.

[19] R.S. Evans, D.C. Classen, S.L. Pestotnik, H.P. Lundsgaarde, and J.P. Burke, "Improving Empiric Antibiotic Selection Using Computer Decision Support," Archives of Internal Medicine, vol. 154, pp. 878-884, 1994.

[20] S. Andreassen, L. Leibovici, H.C. Schoenheyder, K.G. Olesen, and B. Kristensen, "Decision Support Systems in Bacteremia: Evaluation of a Prototype for Empirical Treatment of Danish Patients with Urosepsis," Proc. Bi-Nat'l Israel-Denmark Symp. Optimal Antibiotic Treatment of Severe Bacterial Infections: The Real Issues, Nov. 1996.

[21] D.J. Spiegelhalter, "Probabilistic Expert Systems in Medicine," Statistical Science, vol. 2, pp. 3-44, 1987.

[22] S. Andreassen, "Planning of Therapy and Tests in Causal Probabilistic Networks," Artificial Intelligence in Medicine, pp. 227241, 1992. 
[23] R. Montironi, W.F. Whimster, Y. Collan, P.W. Hamilton, D Thompson, and P.H. Bartels, "How to Develop and Use a Bayesian Belief Network," Clinical Pathology, vol. 49, pp. 194201, 1996.

[24] D.E. Hechermann, B. Horvitz, and E. Nathwan, "Toward Normative Expert Systems: Part I. The Pathfinder Project," Information in Medicine, vol. 31, pp. 90-105, 1992.

[25] S. Andreassen, F.V. Jensen, S.K. Andersen, B. Falck, U. Kjaerulff, M. Woldbye, A. Sørensen, A. Rosenfalck, and F. Jensen, "MUNIN: An Expert EMG Assistant," Computer-aided Electromyography and Expert Systems, J.E. Desmedt, ed., Elsevier Science, pp. 255-277, 1989.

[26] S. Andreassen, J.J. Benn, R. Hoverka, K.G. Olesen, and E.R. Carson, "A Probabilistic Approach to Glucose Prediction and Insulin Dose Adjustment: Description of a Metabolic Model and Pilot Evaluation Study," Computional Methods of Programming in Biomedicine, pp. 153-165, 1994.

[27] L. Leibovici, G. Alpert, O. Kalter-Leibovici, and Y.L. Danon, "A Clinical Model for Diagnosis of Bacterial Urinary Tract Infection in Young Women," Archives of Internal Medicine, vol. 149, pp. 2,0482,050, 1989.

[28] R. Arav-Boger, L. Leibovici, and Y.L. Danon, “Urinary Tract Infections with Low and High Colony Counts in Young Women: Spontaneous Remission and Single-Dose vs. Multiple Day Treatment," Archives of Internal Medicine, vol. 154, pp. 300-304, 1994.

[29] L. Leibovici, S. Greeshtain, O. Cohen, and A.J. Wysenbeek, "Toward Improved Empiric Treatment of Moderate to Severe Urinary Tract Infection," Archives of Internal Medicine, vol. 152, pp. 2,481-2,486, 1992.

[30] C.M. Kunin, Urinary Tract Infections: Detection, Prevention, and Management, fifth ed., p. 5. Baltimore: Williams \& Wilkins, 1996.

[31] B.A. Lipsky, "Urinary Tract Infections in Men: Epidemiology, Pathophysiology, Diagnosis and Treatment," Annals of Internal Medicine, vol. 110, pp. 138-150, 1989.

[32] C.M. Kunin, "Urinary Tract Infections in Females," Clinical Infectious Diseases, vol. 18, pp. 1-12, 1994.

[33] D. Kaye, "Urinary Tract Infections in the Elderly," Bulletin New York Academy of Medicine, vol. 56, pp. 209-217, 1980.

[34] J.A. Boscia, W.D. Kobasa, E. Abrutyn, M.E. Levison, A.M. Kaplan, and D. Kaye, "Lack of Association Between Bacteriuria and Symptoms in the Elderly," Am. J. Medicine, vol. 81, pp. 979-982, 1986.

[35] G.L. Mandell and J.E. Bennet, Principles and Practice of Infectious Diseases, fourth ed., R. Dolin, ed., pp. 662-690. New York: Churchill Livingstone, 1996.

[36] J.A. Boscia, W.D. Kobasa, R.A. Knight, E. Abrutyn, M.E. Levison, and D. Kaye, "Epidemiology of Bacteriuria in an Elderly Ambulatory Population," Am. J. Medicine, vol. 80, pp. 208-214, 1986.

[37] D. Grahn, D.C. Norman, M.L. White, M. Cantrell, and T.T. Yoshikawa, "Validity of Urinary Catheter Specimen for Diagnosis of Urinary Tract Infection in the Elderly," Archives of Internal Medicine, vol. 145, pp. 1,858-1,860, 1985.

[38] U. Setia, I. Serventi, and P. Lorenz, "Nososcomial Infections Among Patients in a Long-Term Care Facility: Spectrum, Prevalence, and Risk Factors," Am. J. Infection Control, vol. 13, pp. 57-62, 1985

[39] J.W. Warren, D. Damron, J.H. Tenney, J.M. Hoopes, B. Deforge, and H.L. Muncie, "Fever, Bacteremia, and Death as Complications of Bacteriuria in Women with Long-Term Urethral Catheters," J. Infectious Diseases, vol. 155, pp. 1,151-1,154, 1987.

[40] J. Magaziner, J.H. Tenney, B. Deforge, J.R. Hebel, H.L. Muncie, and J.W. Warren, "Prevalence and Characteristics of Nursing Home Acquired Infections in the Aged," J. Am. Geriatriac Soc., vol. 39, pp. 1,071-1,078, 1991.

[41] T. Bregenzer, R. Frei, A.F. Widmer, W. Seiler, W. Probst, G. Mattarelli, and W. Zimmerli, "Low Risk of Bacteremia during Catheter Replacement in Patients with Long-Term Urinary Catheters," Archives of Internal Medicine, vol. 157, pp. 521-525, 1997.

[42] L.E. Nicolle, J. Bjornson, G.K.M. Harding, and J.A. MacDonnel, "Bacteriuria in Elderly Institutionalized Men," New England J. Medicine, vol. 309, pp. 1,420-1,425, 1983.

[43] C.M. Kunin, Q.F. Chin, and S. Chambers, "Indwelling Urinary Catheters in the Elderly: Relaton of 'Catheter Life' to Formation of Encrustations in Patients with and without Blocked Cathaters," Am. J. Medicine, vol. 82, pp. 405-409, 1987.
[44] R.B. Breitenbucher, "Bacterial Changes in the Urine Samples of Patients with Long-Term Indwelling Catheters," Archives of Internal Medicine, vol. 144, pp. 1,585-1,588, 1984.

[45] L.E. Nicolle, W.J. Mayhew, and L. Bryan, "Prospective Randomized Comparison of Therapy and No Therapy for Asymptomatic Bacteriuria in Institutionalized Elderly Women," Am. J. Medicine, vol. 83, pp. 27-31, 1987.

[46] V. Tzias, A.S. Dontas, G. Petrikkos, M. Papapetropoulou, J. Dracopoulos, H. Giamarellou, "Three Day Antibiotic Therapy in Bacteriuria of Old Age.," J. Antimicrobial Chemotherapy, vol. 26, pp. 705-711, 1990.

[47] J.G. Ouslander, B. Greengold, and S. Chen, "Complications of Chronic Indwelling Urinary Catheters among Male Nursing Home Patients: A Prospective Study," J. Urology, vol. 138, pp. 1,191-1,195, 1987.

[48] R. Gleckman, N. Blagg, D. Hibert, A. Hall, M. Crowley, A. Pritchard, and W. Warren, "Catheter-Related Urosepsis in the Elderly: A Prospective Study of Community-Derived Infections," J. Am. Geriatriacs, vol. 30, pp. 255-257, 1982.

[49] C.M. Kunin, Urinary Tract Infections: Detection, Prevention, and Management, fifth ed., pp 241-244. Baltimore: Williams \& Wilkins, 1996.

[50] D.E. Craven, L.M. Kunches, D.A. Lichtenberg, N.R. Kollisch, A. Barry, T.C. Heeren, and W.R. McCabe, "Nosocomial Infection and Fatality in Medical and Surgical Intensive Care Unit Patients," Archives of Internal Medicine, vol. 148, pp. 1,161-1,168, 1988.

[51] J.-L. Vincent, D.J. Bihari, P.M. Suter, H.A. Bruining, J. White, M.-H. Chanoin, M. Wolff, R.C. Spencer, and M. Hemmer, "The Prevalence of Nosocomial Infection in Intensive Care Units in Europe: Results of the European Prevalence of Infection in Intensive Care (EPIC) Study," J. Am. Medical Assoc., vol. 274, pp. 639-644, 1995.

[52] W.R. Gransden, L. Leibovici, S.J. Eykyn, S.D. Pitlik, Z. Samra H. Konigsberger, M. Drucker, and I. Phillips, "Risk Factors and a Clinical Index for Diagnosis of Pseudomonas Aeruginosa Bacteremia," J. Clinical Microbiology Infection, vol. 1, pp. 119-123, 1996.

[53] Anonymous. "Hospitals, Nursing Homes and Day Care Units in Israel: Statistical Data by Institution and Department," Health Ministry, Computing and Information Service (Hebrew), 1996.

[54] Anonymous. Ann. Statistical Report, vol. 48, The Central Office for Statistics (Hebrew), 1997.

[55] J. Kohler-Ockmore and R.C. Feneley, "Long Term Catheterization of the Bladder: Prevalence and Morbidity," British J. Urology, vol. 77, pp. 347-51, 1996.

[56] D.J. Hunter A. Berra-Unamuno, and A. Martin-Gordo, "Prevalence of Urinary Symptoms and Other Urological Conditions in Spanish Men 50 Years Old or Older," J. Urology, vol. 155, pp. 1,9651,970, 1996.

[57] D. Rothenbacher, G. Bode, G. Adler, and H. Brenner, "Use of Commonly Prescribed Antibiotics Is Not Associated with Prevalence of Helicobacter Pylori Infections in Adults," Scandinavian J. Gastroenterology, vol. 32, pp. 1,069-1,090, 1997.

[58] D. Guillemot, C. Carbon, F. Vauzelle-Kervroedan, B. Balkau, P. Maison, G. Bouvenot, and E. Eschwege, "Inappropriateness and Variability of Antibiotic Prescription among French Office-Based Physicians," J. Clinical Epidemiology, vol. 51, pp. 61-68, 1998.

[59] C.M. Kunin, L. White VanArsdale, and T.H. Hua, "A Reassessment of the Importance of 'Low-Count' Bacteriuria in Young Women with Acute Urinary Symptoms," Annals of Internal Medicine, vol. 119, pp. 454-460, 1993.

[60] L. Leibovici, R. Arav-Boger, and Y.L. Danon, "A Clinical Model for Diagnosis of Urinary Tract Infection in Young Women," Archives of Internal Medicine, vol. 153, pp. 1,011-1,015, 1993.

[61] H.L. Corwin and M.D. Silverstein, "Microscopic Hematuria," Clinical Laboratory Medicine, vol. 8, pp. 601-610, 1988.

[62] M. Laville, P. Roy, H. Pellet, J. Fabry, and P. Zech, "Microscopic Hematuria in Adults: Prevalence and Associated Factors," Presse Medicine, vol. 20, pp. 545-50, 1991 (in French).

[63] M. Korpela, J. Mustonen, A. Heikkinen, H. Helin, and A. Pasternack, "Isolated Microscopic Hematuria in Patients with Rheumatoid Arthritis Compared with Age and Sex Matched Controls. A Population Based Study," J. Rheumatology, vol. 22, pp. 427-431, 1995.

[64] G.G. Wolfs, J.A. Knottnerus, and R.A. Jangtnegt, "Prevalence and Detection of Micturition Problems among 2,734 Elderly Men," J. Urololgy, vol. 152, pp. 1,467-1,470, 1994. 
[65] S. Woolhandler, R.J. Pels, D.H. Bor, D.U. Himmelstein, and R.S Lawrence, "Dipstick Urinalysis Screening of Asymptomatic Adults for Urinary Tract Disorders. I. Hematuria and Proteinuria," J. Am. Medical Assoc., vol. 262, pp. 1,214-1,219, 1989.

[66] P. Froom, J. Ribak, and J. Benbassat, "Significance of Microhematuria in Young Adults," British Medical J., vol. 288, pp. 20-22, 1984

[67] N. Alwall and A. Lohi, "A Population Study on Renal and Urinary Tract Disease," Acta Medica Scandinavica, vol. 194, pp. 529-535, 1973.

[68] E.M. Messing, T.B. Young, V.B. Hunt, S.E. Emoto, and J.M. Webbie, "The Significance of Asymptomatic Microhematuria in Men 50 or More Years Old: Findings of a Home Screening Study Using Urinary Dipsticks," J. Urology, vol. 137, pp. 919-922, 1987.

[69] H. Eriksson, K. Svardsudd, B. Larsson, L. Welin, L.-O. Ohlson, and L. Wilhemsen, "Body Temperature in General Population Samples," Acta Medica Scandinavica, vol. 217, pp. 347-352, 1985

[70] J.R. Eskerud, E. Laerum, H. Fagerthun, P.K.M. Lunde, and A.A Naes, "Fever in General Practice. I. Frequency and Diagnoses," Family Practice, vol. 9, pp. 263-279, 1992.

[71] M.-C. Corti, J.M. Guralnik, M.E. Salive, and J.D. Sorkin, "Serum Albumin Level and Physical Disability as Predictors of Mortality in Older Patients," J. Am. Medical Assoc., vol. 272, pp. 1,036-1,042, 1994.

[72] R.F. Gillum, D.D. Ingram, and D.M. Makuc, "White Blood Cell Count, Coronary Heart Disease, and Death: The NHANES I Epidemiologic Follow-Up Study," Am. Heart J., vol. 125, pp. 855863, 1993.

[73] P. Wetteland, M. Røger, H.E. Solberg, and O.H. Iversen, "Population-Based Erythrocyte Sedimentation Rates in 3,910 Subjectively Healthy Norwegian Adults: A Statistical Study Based on Men and Women from the Oslo Area," J. Internal Medicine, vol. 240, pp. 125-131, 1996.

[74] F. Carlstedt, L. Lind, and B. Lindahl, "Proinflammatory Cytokines, Measured in a Mixed Population on Arrival in the Emergency Department, Are Related to Mortality and Severity of Disease," J. Internal Medicine, vol. 242, pp. 361-365, 1997.

[75] C.M. Kunin and J.E. DeGroot, "Self-Screening for Significant Bacteriuria: Evaluation of Dipstrip Combination Nitrite/Culture Test," J. Am. Medical Assoc., pp. 1,349-1,353, 1975.

[76] M.A. Pfaller and F.P. Koontz, "Laboratory Evaluation of Leukocyte Esterase and Nitrite Test for the Detection of Bacteriuria," J. Clinical Microbiology, vol. 21, pp. 840-842, 1985.

[77] O.R. Madsen, M. Faber, L. Phillipsen, and N. Frimodt-Møller, "Demonstration of Bacteriuria in Elderly Hospitalized Patients: Comparison between Leukocyte and Nitrite Strip Tests and Culture," Ugeskr Laeger, vol. 154, pp. 3,682-3,686, 1992 (in Danish).

[78] L. Leibovici, I. Shraga, M. Drucker, H. Konigsberger, Z. Samra, and S.D. Pitlik, "The Benefit of Appropriate Empirical Antibiotic Treatment in Patients with Bloodstream Infection," J. Internal Medicine, vol. 244, pp. 379-386, 1998.

[79] R.B. Cattell, The Scientific Use of Factor Analysis. New York: Plenum, 1978.

[80] D. Spiegelhalter and S.L. Lauritzen, "Sequential Updating of Conditional Probabilities on Directed Graphical Structures," Networks, vol. 20, pp. 579-605, 1990.

[81] D. Heckermann, "Bayesian Networks for Data Mining," Data Mining and Knowledge Discovery, vol. 1, pp. 79-119, 1997.

[82] R.A. Howard and J.E. Matheson, "Influence Diagrams," Readings on the Principles and Applications of Decision Analysis, R.A. Howard and J.E. Matheson, eds., vol. 2, pp. 719-762. Menlo Park, Cailf.: Strategic Decision Group, 1984.

[83] V. Hasselblad and D.C. McCrory, "Meta-Analytic Tools for Medical Decision Making: A Practical Guide," Medical Decision Making, vol. 15, pp. 81-96, 1995

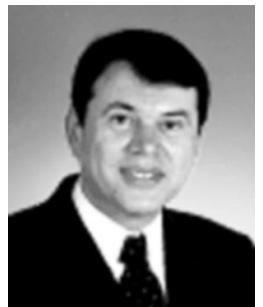

Leonard Leibovici is the head of the Department of Internal Medicine E, Rabin Medical Center, Beilinson Campus, Petah-Tiqva; and professor of medicine on the Sackler Faculty of Medicine, Tel-Aviv University, Ramat-Aviv, TelAviv, Israel. His main research interests are bacterial infections, antibiotic treatment, and computerized decision support.

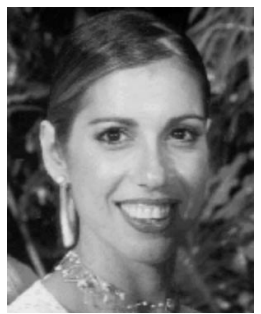

Michal Fishman, MD, graduated from the Sackler Faculty of Medicine, Tel-Aviv University, Israel. She completed her residency in internal medicine and is now a fellow in gastroentorology. She developed the urinary tract infection and part of the lung infection sites in the network as her basic science project during her residency in internal medicine.

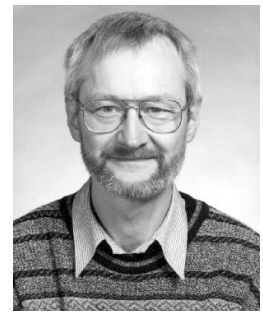

Henrik C. Schønheyder received the MD degree and the MDsc, respectively, in 1977 and 1987, from the University of Aarhus. From 1980-1987, he was an associate professor at the Institute of Medical Microbiology at the University of Aarhus. From 1987-1994, he was a specialist training in clinical microbiolgy. In 1998, he was a consultant at the Department of Clinical Microbiology at Aalborg Hospital and, in 1999, he was a professor of clinical microbiology, the Faculty of Health Sciences at the University of Aarhus. He has published more than 120 publications in peer-reviewed journals with an emphasis on fungal infections and bacteremia.

Christian Riekehr's bio and photo are not available.

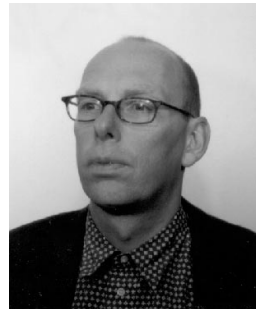

Brian Kristensen, MD, graduated from the University of Aarhus in 1987. From 1990-2001, he is a specialist training in clinical microbiology. $\mathrm{He}$ is a senior registrar in the Department of Clinical Microbiology at Aalborg Hospital. He has published more than 15 publications in peerreviewed journals with a special emphasis on bacteremia, antibiotic resistance, and decision support systems.

Ilana Shraga, MD, graduated from the Riga Faculty of Medicine, Latvia. She completed her residency in internal medicine at Beilinson Campus, Rabin Medical Center. Her part in the project was the collection and synthesis of data on side-effects and cost of treatment.

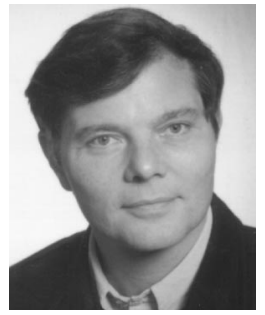

Steen Andreassen received the MSc degree from the Technical University of Denmark in 1973, and the PhD degree in electronic engineering in 1976 from the Department of Electronic Engineering, Technical University of Denmark and the Institute of Neurophysiology, University of Copenhagen, Denmark. In 2000, he received the degree of DrTech. From 1977 to 1978, he was a post-doctoral fellow at the Institute of Physiology, University of Alberta, Canada, and, in 1978, he joined the Department of Medical Informatics and Image Analysis at Aalborg University, Denmark. He is now a reader at Aalborg University. His scientific interest is the development of medical decision support systems within the areas of diabetes, intensive care, anesthesiology, and antibiotic therapy. He has close to 200 publications in refereed journals and international conferences. He is vice president of the Danish Society for Biomedical Engineering and president of the European Society for Artificial Intelligence in Medicine. $\mathrm{He}$ is a member of the editorial board of Diabetes, Nutrition and Metabolism. 